Hispania Sacra, LX

122, julio-diciembre 2008, 487-505, ISSN: 0018-215-X

La administración

\title{
LA SECULARIZACIÓN DE DOCTRINAS \\ EN EL ARZOBISPADO DE MÉXICO: REALIDADES INDIANAS \\ Y RAZONES POLÍTICAS, 1700-1749
}

POR

\author{
RODOLFO AGUiRRE \\ IISUE-UNAM
}

\begin{abstract}
RESUMEN
El presente trabajo tiene como objetivo contrastar los argumentos expuestos en las juntas de Madrid encargadas de discutir la situación del clero regular en Indias, previas a la real cédula de 1749 sobre secularización de curatos, con la realidad de los mismos en la región mexicana. Las juntas, compuesta por ministros del rey y los arzobispos de México y Lima, tuvo como meta demostrar la necesidad de separar de los curatos a los frailes debido a la relajación de sus votos y la independencia que mostraban ante cualquier autoridad. No obstante, la realidad mostraba que desde 1700, en el arzobispado de México, sus prelados habían logrado sujetar a los frailes encargados de los curatos de indios. Al comparar los argumentos vertidos en Madrid y la cédula de 1749 con los cambios ocurridos en el arzobispado de México durante la primera mitad del siglo XVIII queda claro que las medidas decretadas por Fernando VI sobre las doctrinas indianas obedecieron principalmente a razones políticas externas a la Nueva España, más que internas.
\end{abstract}

PALABRAS CLAVE: Secularización, curatos, arzobispado de México, siglo XVIII, cédula de 1749 .

\section{THE SECULARIZACIÓN OF PARISHES IN THE ARCHBISHOPRIC OF MEXICO: INDIAN REALITIES AND POLITICAL REASONS, 1700-1749}

\section{ABSTRAC}

The present work must like objective resist the arguments set out in the 
meetings of Madrid in charge to discuss the situation of the regular clergy in Indians, previous to the real law of 1749 on secularización of parishes, with the reality of the same in the Mexican region. The meetings, composed by ministers of king and the archbishops of Mexico and Lima, had as it puts to demonstrate the necessity to separate of the parishes to the friars due to the relaxation of his votes and the independence that showed before any authority. However, the reality showed that from 1700, in the archbishopric of Mexico, their prelates had managed to hold to the friars in charge of the parishes of Indians. When comparing the arguments spilled in Madrid and the law of 1749 with the changes happened in the archbishopric of Mexico during first half of century XVIII it is clear that the measures decreed by Fernando VI on the Indian parishes obeyed mainly to external political reasons to the New Spain, than more internal.

KEY WORDS: Secularization, parishes, archbishopric of Mexico, century XVIII, law of 1749 .

Recibido/Received 08-01-2008

Aceptado/Accepted 25-02-2008

Cuando, en la primera mitad del siglo XVI, la corona española encomendó a las órdenes mendicantes la evangelización de la población indígena de Nueva España, haciendo a un lado al clero secular, se inició una confrontación entre ambos cleros que sólo se solucionó hasta la segunda mitad del siglo XVIII, gracias a la orden de Fernando VI de secularizar todas las doctrinas en manos de frailes. Entre 1524, cuando llegó el primer grupo franciscano evangelizador, y la cédula de 4 de octubre de 1749 que decretó la secularización de doctrinas ${ }^{1}$, hubo muchas discusiones, polémicas e intentos en Nueva España por quitar a los frailes la administración espiritual de los indios.

Salvo en tres momentos del siglo XVII, cuando varios frailes fueron separados en algunas doctrinas de los obispados de Puebla, Yucatán y Oaxaca ${ }^{2}$, la fuerza y los recursos de las órdenes mendicantes fueron tales que lograron impedir cualquier intento mayor. No obstante, ello no significó que todo siguiera igual hasta 1749, ni que el éxito que después de este año hubo en la secularización se debiera fundamentalmente a lo actuado por el nuevo arzobispo de México y el virrey Revillagidedo, como el primero presumió en Madrid. En realidad, la aplicación de la cédula de 4 de octubre se dio en mejores condiciones que todos los intentos anteriores, pues durante la primera mitad del siglo XVIII las doctrinas habían sido objeto de una mayor sujeción a la autoridad arzobispal, a la vez que la feligresía no india de las parroquias había minado la otrora gran autoridad de los religiosos en los pueblos de indios.

\footnotetext{
${ }^{1}$ En este trabajo se usara el término «parroquias» para hablar indistintamente de aquellas administradas por frailes o por clérigos, «curatos» para hablar de las parroquias bajo cuidado del clero secular $\mathrm{y}$ «doctrinas» para aquellas que estaban a cargo de los frailes.

2 Antonio RuBial, «La mitra y la cogulla. La secularización palafoxiana y su impacto en el siglo XVII», en Relaciones. Estudios de Historia y sociedad 73 (1998) 239-272.

Hispania Sacra, LX

122, julio-diciembre 2008, 487-505, ISSN: 0018-215-X
} 
El objetivo de las siguientes páginas es demostrar que el éxito de la secularización iniciada en 1749 se debió a razones más profundas que sólo a la habilidad política del arzobispo y del virrey, y que para entonces, el clero regular del arzobispado de México, a diferencia de sus antecesores del siglo XVII, había sufrido un fuerte desgaste en su independencia ante la autoridad arzobispal y en su presencia ante la sociedad.

El arzobispado de México, como el resto de las diócesis novohispanas, había tenido cambios importantes entre el siglo XVI y principios del XVIII, entre ellos la consolidación de sus instituciones eclesiásticas, el equilibrio de poder entre ambos cleros o el aumento de expectativas de un clero secular más numeroso y dinámico. De 1680 a 1750 Nueva España vivió un crecimiento económico gracias a un aumento en la producción de la plata, de la industria y de la población, así como la ocupación del norte cercano ${ }^{3}$. Todo esto habría tenido como fundamento la formación de una economía interna en el siglo XVII, encabezada por la población española ${ }^{4}$. En lo que al mundo parroquial se refiere, la feligresía era más numerosa gracias a la recuperación demográfica ${ }^{5}$. Hay claros indicios de que, en términos porcentuales, los españoles y los mestizos crecieron más que los indígenas. En este sentido, la composición social de las feligresías parroquiales era distinta con respecto a épocas anteriores. Para la primera mitad del siglo XVIII varias de las doctrinas de «indios» presentaban nuevas condiciones: una población mestiza o española que hacía sentir su presencia en las cabeceras o en haciendas y ranchos de la localidad.

En cuanto a la proporción doctrinas/curatos de clérigos presenciamos un movimiento inverso; es decir: menos doctrinas y más curatos. Aunque en el periodo aquí estudiado ninguna doctrina del arzobispado fue secularizada, cambios en su organización y la desaparición de otras ocasionaron que de 222 que había hacia $1673^{6}$ disminuyeron a 166 hacia 1740, aproximadamente. En cambio un crecimiento importante se dio en los curatos de clérigos, pues si en 1670 se contabilizaban 74 , en las décadas siguientes se agregaron por lo me-

\footnotetext{
${ }^{3}$ David A. BRADING, «El mercantilismo ibérico y el crecimiento económico en la América Latina del siglo XVIII», en: E. Florescano (comp.) Ensayos sobre el desarrollo económico de México y América Latina (1500-1975). México, Fondo de Cultura Económica, 1987, pp. 293-314.

${ }^{4}$ Enrique FLORESCANO e Isabel GIL, «La época de las reformas borbónicas y el crecimiento económico. 1750-1808», en: Historia General de México, México, El Colegio de México, 1987, tomo I, p. 480 .

${ }^{5}$ M. MiÑo GrIJALVA, El mundo novohispano. Población, ciudades y economía, siglos XVII y XVIII, México, Fondo de Cultura Económica-El Colegio de México, 2001, p. 128: «La migración indígena a tierras bajas comenzó a principios del siglo XVII y se aceleró en el XVIII, especialmente después de 1738 , ante los efectos del matlazahuatl.»

${ }^{6}$ Archivo General de Indias de Sevilla (AGI en adelante) México 338.
} 
nos otros 23, llegando a ser casi 100 hacia $1740^{7}$. El aumento fue de hasta en un $28 \%$. Aun así, las órdenes regulares tenían $50 \%$ más parroquias que los clérigos ${ }^{8}$.

La creación de nuevos curatos fue resultado de la conversión de pueblos de visita en cabeceras. Una mayor demanda de servicios espirituales de las diferentes feligresías y la incapacidad de los curas para satisfacerla fueron motivos determinantes para ese proceso. Es indudable, pues, el efecto que en la vida parroquial tuvo el aumento demográfico en los pueblos, así como el interés de muchas haciendas del arzobispado por la fundación de nuevas cabeceras parroquiales, cercanas a ellas y que atendieran las necesidades espirituales de sus trabajadores, cada vez en aumento, causando inquietud en los curas por la despoblación de los pueblos.

En el caso de las doctrinas de regulares, durante la primera mitad del siglo XVIII hubieron de enfrentar y aceptar nuevas realidades. En primer lugar, la intervención de otras autoridades o de los feligreses, para subdividir doctrinas; en segundo, el intento del arzobispo Lanciego de convertir las misiones de Pánuco y de la Huasteca en doctrinas; y, en tercero, los intentos de los mismos clérigos por minar su presencia, tanto en doctrinas rurales como en importantes plazas del arzobispado, como Querétaro.

El asunto de la subdivisión de doctrinas podía seguir un patrón similar al de los curatos; es decir, un sector de la feligresía acudía directamente al arzobispo o al virrey para solicitar la creación de una nueva doctrina, alegando deficiencia en la administración espiritual. No faltaron acusaciones al mismo arzobispo Lanciego de promover la división de doctrinas, sobre todo por parte de los franciscanos. En otras ocasiones la subdivisión de una doctrina no tenía éxito, y a lo más que se llegaba era a erigir una ayuda de parroquia con vicario fijo, no por falta de entusiasmo del arzobispo, sino por la escasez de rentas. Respecto a las misiones del norte del arzobispado no dejaron de estar en la agenda del activo arzobispo Lanciego, pues, de hecho, su objetivo fue convertirlas a doctrinas, buscando con ello tener más atribuciones. A raíz de su visita a la Huasteca, Lanciego constató que los ministros de las misiones franciscanas de Tampico no tenían presentación ni del virrey, ni de ningún arzobispo, violando las leyes del real patronato al respecto, sobre todo la ley 3 , título 15 del libro I de la $R e$ -

\footnotetext{
${ }^{7}$ Rodolfo AguirRe Salvador, «Curatos y doctrinas del arzobispado de México en la primera mitad del siglo XVIII». Inédito.

${ }^{8}$ Cifras que desmienten estudios anteriores que ven precisamente una relación inversa, como por ejemplo: W. B. TAYLOR, Ministros de lo sagrado. Sacerdotes y feligreses en el México del siglo XVIII. México, El Colegio de Michoacán-Secretaría de Gobernación-El Colegio de México, tomo I, p. 120: «A pesar de una ola de secularizaciones a fines del siglo XVI, los mendicantes lograron conservar la tercera parte de las entidades parroquiales en ambas diócesis».
}

Hispania Sacra, LX

122, julio-diciembre 2008, 487-505, ISSN: 0018-215-X 
copilación de leyes de Indias ${ }^{9}$. Por ello, en 1720, el arzobispo le propuso al virrey decretar la conversión de las misiones en doctrinas, para seguir todos los requisitos de presentación de ministros ${ }^{10}$.

Pero si las cosas no iban tan bien en las doctrinas rurales o en las alejadas misiones para el clero regular, ¿por qué esperar algo mejor en grandes doctrinas con verdaderos enclaves de clérigos sin beneficios pero con muchas expectativas? Veamos lo que sucedía en Querétaro, la segunda ciudad del arzobispado, hacia 1724, cuando una disputa entre los franciscanos y los clérigos vecinos por la procesión de Corpus Christi puso al descubierto el temor de los primeros por ser desplazados de la cura de almas. Los franciscanos, titulares de esa doctrina, explicaron al virrey que desde la fundación de la ciudad el convento franciscano se hizo cargo de sacramentar a los indios, por indultos apostólicos, y al resto de la población, por comisión de los arzobispos, pero que hacia 1710 :

[...] habiendo tomado algún cuerpo el número de eclesiásticos seculares de aquella ciudad, se valieron de la voz de los vecinos de ella, padres y parientes de los susodichos, para que, a su representación, se dignase su majestad de encomendarles el curato de dicha ciudad en cuanto a españoles, negros, mestizos, mulatos, separándolo del de los indios, que es el que sólo querían dejar a los religiosos de dicho convento, para lo cual maquinaron razones e inconvenientes, que si no bastaron a inclinar a su propósito el real ánimo de su majestad, a lo menos fueron suficientes a constituirlo en duda de lo más conveniente, y a fin de salir de ella y elegir lo mejor, expidió su real cédula de 15 de febrero de 1701 en que pidió informe al excelentísimo señor virrey que entonces era de esta Nueva España y a la real audiencia de ella $[\ldots]^{11}$.

${ }^{9}$ Recopilación de leyes de los reynos de las Indias 1681. México, Escuela Libre de Derecho-Miguel Ángel Porrúa, 1987. Tomo primero, libro I, título XV, ley III, p. 76. En la parte central de esa ley se específica que: «Ordenamos y mandamos que en cuanto a remover y nombrar los provinciales y capítulos de las religiones, religiosos doctrineros, guarden y cumplan lo que está dispuesto por las leyes del patronazgo real de las Indias, sin ir ni pasar contra ello, en forma alguna. Y demás de esto, siempre que hubieren de proveer algún religioso para doctrina que tengan a su cargo, ora sea por promoción del que la sirviere, ó por fallecimiento ó otra causa, el provincial y capítulo hagan nominación de tres religiosos, los que les parecieren más convenientes para la doctrina, sobre que les encargamos las conciencias, y esta nominación se presente ante vuestro virrey, presidente o gobernador [...]».

10 Archivo General de la Nación de México (AGNM en adelante) Clero Regular y Secular Año: 1719-1721. Vol. 93, f. 197: El abogado fiscal del virrey fue de la opinión que, aunque la población de las misiones había aumentado considerablemente, sobre todo de gentes de razón, y ello justificaría su transformación a doctrinas, antes había que pedir al provincial franciscano si tenía algo que alegar al respecto. El virrey asintió con esta opinión y así lo ordenó, aunque no sabemos aun hasta donde se cumplieron los deseos de Lanciego.

${ }^{11}$ AGN Clero Regular y Secular 148,f. 402 y Bienes Nacionales 853, exp. 2. Después de la ciudad de México, cuyo número de clérigos es incomparable por supuesto, es muy posible que el amor conjunto de los mismos se halla asentado en Querétaro, por lo que al arzobispado se refiere. Hacia 1711 se contabilizaban al menos 29 clérigos, incluyendo al juez eclesiástico local. 
En consecuencia, hacia 1705 los clérigos lograron que se les diera en ínterin la administración de los españoles; y no contentos con ello, disputaron a los frailes la precedencia en la procesión de Corpus Christi, iniciando un nuevo pleito ante el vice-patrono; como resultado, en 1708 «....se sirvió vuestra excelencia...se informase a su majestad lo conveniente que sería que se erigiesen dos o más parroquias de curas seculares para gente española y demás ladinos de dicha ciudad, pero que en el ínterin...no se hiciese novedad...», e incluso, se ordenó sobreseer la cédula que daba a los clérigos la administración interina de los españoles.

¿En cuántas doctrinas los clérigos compitieron por los espacios de culto, cómo en Querétaro? Aun más, esos mismos núcleos locales clericales carecían de rentas eclesiásticas significativas y de obvenciones parroquiales, una razón más para esperar una futura secularización de las doctrinas en las que ellos pudieran sustituir a los frailes. Pero, ¿cuál era la realidad de los ingresos parroquiales en el arzobispado? Veamos.

Los ingresos parroquiales eran un asunto de sumo interés para cualquier cura. Igual lo era para las autoridades al tener que asegurar un mínimo de rentas pues ello podía determinar una estancia prolongada de los curas; de hecho no se fundaba un nuevo curato si no se garantizaba un ingreso mínimo al nuevo titular. A nivel político, las rentas de las doctrinas, así como los bienes conventuales despertaban mucho interés en propios y extraños. En el clero secular, comenzando por la mitra, las rentas de los regulares no dejaba de ser un asunto siempre vigente, no sólo por el antiguo problema del no pago del diezmo por los religiosos, sino también porque la diferencia numérica entre doctrinas y curatos, aunado a la falta de beneficios estables para la clerecía en crecimiento, hacia de la secularización de doctrinas una necesidad creciente. Al comparar los promedios de renta entre doctrinas y curatos podemos constatar que eran mayores las de las primeras. Hacia principios del siglo XVIII los promedios eran así:

\section{Promedio anual de ingresos parroquiales en el arzobispado de México hacia 1704}

\begin{tabular}{|l|l|}
\hline Curatos & 1132 pesos \\
\hline Doctrinas agustinas & 1000 pesos \\
\hline Doctrinas dominicas & 1418 pesos \\
\hline
\end{tabular}

Fuentes: AGN Bienes Nacionales

Es evidente que, en general, los recursos que percibían las doctrinas eran mejores, sobre todo los de las doctrinas dominicas. Cabe destacar que la infor- 
mación sobre las doctrinas hay que verla con reservas, por cuanto era difícil comprobar la certeza de ciertos ingresos declarados como «pagos en especie», de los cuales no se llevaba un registro ni había manera de comprobarlos. Pero lo mismo se puede pensar de los curatos de clérigos. Tres décadas más tarde, hacia 1744, la diferencia de rentas entre doctrinas y curatos se hace más acusada, como puede verse en la siguiente tabla:

\section{Promedio anual de ingresos parroquiales en el arzobispado de México hacia 1744}

\begin{tabular}{|l|c|}
\hline Curatos & 1294 pesos \\
\hline Doctrinas franciscanas & 2229 pesos \\
\hline Doctrinas agustinas & 1675 pesos \\
\hline Doctrinas dominicas & 1492 pesos \\
\hline
\end{tabular}

Fuentes: William Taylor, Ministros de lo sagrado...tomo II

Los niveles de renta de las doctrinas superan fácilmente a los curatos, que se hallan en el último lugar. Ante tal fenómeno es más fácil entender a arzobispos como Lanciego, que sabían muy bien que con el traspaso de doctrinas se ayudaría en mucho a dar ocupación e ingresos seguros a por lo menos 160 clérigos, sin contar con la creación de cargos sub-parroquiales derivados de los nuevos curatos secularizados, además de que sería más fácil cobrar el diezmo, el subsidio eclesiástico y pedir donativos de todo tipo, a favor de la mitra o de la corona.

Y es que la creación de nuevos beneficios y empleos eclesiásticos en el arzobispado se había convertido en una preocupación de primer orden para los prelados. ¿Por qué? Porque la clerecía de la primera mitad del siglo XVIII crecía en número, buscaba más oportunidades de ocupación, presionaba para ocupar más capellanías de misas, se desplazaban de una provincia a otra buscando «conveniencias» y pedía a sus superiores, especialmente a sus prelados, mejores posibilidades de ingresos para vivir conforme a su estado eclesiástico.

En la ciudad de México, en especial, se concentraba el 50\% de la clerecía: tanto los clérigos candidatos a promoverse al alto clero como aquellos que simplemente buscaban un empleo estable buscaban residir permanentemente en espera de una oportunidad, aun si ello implicaba pasar incomodidades de todo tipo. La competencia no era sólo entre los originarios del arzobispado, sino también entre clérigos de otras diócesis que migraban para buscar en mayores posibilidades de ocupación. Y es que la capital novohispana albergaba el mayor número de instituciones y dependencias eclesiásticas que cualquier otra ciudad de Nueva España. Aunque para la primera mitad del siglo XVIII se llegó al apo- 
geo en la fundación de capellanías de misas, sólo un sector de clérigos disfrutaba de sus rentas.

Es claro que una minoría acaparaba un gran número de esas fundaciones. La mayoría de los capellanes sólo tenía la renta de una capellanía de no más de 150 o 200 pesos anuales, si es que se cobraba. Con todo, las decenas de cargos, nombramientos y empleos de mediano y bajo rango no eran, ni con mucho, suficientes para poder ocupar a todos. Además, la mayoría de esos empleos eran temporales y no resolvían permanentemente el sustento de sus tiulares.

En las parroquias del interior del arzobispado de México, las oportunidades para el clérigo medio eran diferentes, pero no mejores, al haber menos capellanías de misas y cargos de instituciones y más cargos relacionados con la administración de sacramentos.

Tres factores incidieron poderosamente en la primera mitad del siglo XVIII para acrecentar las expectativas de empleo, aunque no tanto los empleos propiamente: el aumento de la población en las parroquias, el crecimiento de los curatos en manos del clero secular y la recaudación del subsidio eclesiástico para Felipe V, que necesitó del nombramiento de jueces eclesiásticos de doctrina. No obstante, los cargos en la provincia no aumentaron tanto como para resolver el problema de la desocupación clerical, pues la mayoría eran, igual que en la capital, actividades temporales: predicadores ambulantes, celebrantes o confesores en algunas fechas especiales de los curatos del arzobispado. Era un hecho que muchos clérigos podían pasar toda su vida en ese tipo de empleos.

Ante esas realidades, a los arzobispos no les quedaba sino usar una y otra vez de las pocas opciones de crear empleos que tenían a su alcance, otorgando licencias para confesar, predicar y celebrar misas, así como fomentar en los curatos los servicios de auxiliares y vicarios de los curas titulares, con la doble intención de mejorar los servicios espirituales del pueblo y de dar ocupación a las nuevas generaciones de clérigos. El arzobispo Lanciego, en especial, generalizó la figura del juez eclesiástico en todo el arzobispado ${ }^{12}$.

Un sector del clero parroquial, siempre presente, era el constituido por los sacerdotes especialistas en lenguas indígenas. La importancia de los clérigos «lenguas» era ambivalente: por un lado, ante el fracaso por erradicar los idiomas indígenas, fueron buscados por los titulares que ignoraban las

\footnotetext{
12 Rodolfo AguirRe SALVADOR, «Los jueces eclesiásticos y la consolidación de la autoridad episcopal en las doctrinas de indios. Arzobispado de México (1700-1748)». Actas de las XI Jornadas Interescuelas/Departamentos de Historia. Tucumán, Universidad Nacional de Tucumán-Facultad de Filosofía y Letras, 2007, disco compacto.

Hispania Sacra, LX

122, julio-diciembre 2008, 487-505, ISSN: 0018-215-X
} 
lenguas ${ }^{13}$. Incluso se les perdonaban carencias en su formación sacerdotal, con tal de tenerlos listos cuando se les necesitará ${ }^{14}$. Por otro lado, los clérigos «lenguas» eran muy subestimados y poco reconocidos ${ }^{15}$. A pesar de su utilidad, su situación económica y social no era proporcional, aun y cuando durante la secularización de las doctrinas, a partir de 1749, fueron un recurso indispensable para la transición.

Otra figura, presente en el arzobispado durante la primera mitad del siglo XVIII, fue la de juez eclesiástico, encargado de hacer cumplir el derecho canónico y dictar sentencia en primera instancia. En los curatos, normalmente los mismos curas adoptaron esa función. Hacia 1723 llegó a haber en el arzobispado hasta 91 jueces eclesiásticos ${ }^{16}$.

Jugaron un papel central en las parroquias, porque tuvieron que hacerse cargo, cada uno en su jurisdicción, de averiguar, regular y cobrar el subsidio eclesiástico a Felipe V. Es un hecho que sin su ayuda, ese proceso fiscal perdía mucha efectividad. El cargo de juez eclesiástico tampoco era vitalicio, sino sólo «por el tiempo de la voluntad» del arzobispo. De particular importancia fueron los jueces de doctrinas, que, a pesar del rechazo de los regulares, se convirtieron en figuras permanentes que coartaron con firmeza el poder que tradicionalmente gozaron los doctrineros. El juez de doctrinas era la presencia real, cotidiana, de la autoridad arzobispal en todos los rincones del arzobispado.

Así las cosas, es evidente que el clero secular del arzobispado de México entró durante el periodo estudiado en un desfase agudo entre las demandas de

13 AGN Bienes Nacionales 1253, exp. 2. Véase por ejemplo la siguiente petición de un cura titular: «Diego López de Salvatierra, beneficiado del partido de Tarasquillo por Su Majestad parezco ante Vuestra Señoría Ilustrísima y digo que, con ocasión de vivir el bachiller Gregorio Cortés, presbítero de este arzobispado en la ciudad de Lerma, jurisdicción de dicho partido, persona de toda suficiencia y que sabe la lengua mexicana y otomí, me valí de él para que me ayudase a la administración de dicho mi beneficio y reconocí ser suficiente, así en la administración de los santos sacramentos como en entender y saber las lenguas que en dicho partido hay de otomí y mexicano y que así mismo es confesor general aprobado por el ilustrísimo señor don Diego Osorio de Escobar y Llamas, arzobispo gobernador que fue de esta ciudad, y así mismo refrendada su licencia por el ilustrísimo y excelentísimo señor don fray Payo de Ribera [...] Y para que dicho bachiller pueda usar de ella y ayudarme en esta santa cuaresma y en lo demás que se ofreciere de la administración de los santos sacramentos en dicho mi beneficio, a Vuestra Señoría Ilustrísima pido y suplico se sirva de mandar se despache título en forma de vicario al dicho bachiller Gregorio Cortés, de dicho mi beneficio de Tarasquillo, en atención a ser persona suficiente y muy necesaria para que me asista como llevo dicho y saber las lenguas...».

${ }^{14}$ En los exámenes incluso los sinodales llegaban a anotar en los registros que ciertos clérigos se les ordenaba porque hacían falta sus conocimientos de lengua, no obstante su deficiencia en el latín u otras materias. Tal fue el caso del presbítero José Armas Pelayo, quien fue ordenado de misa en 1725, a pesar de su deficiencia en el latín, pero gracias a su conocimiento del huasteco, lengua poco común en los dominios del clero secular. AGN Bienes Nacionales 1271, exp. 1, f. 163.

15 Me he acercado al estudio de este sector clerical en: «La demanda de clérigos «lenguas» del arzobispado de México, 1700-1750», en Estudios de Historia Novohispana 35 (2006) pp. 47-70.

${ }^{16}$ Archivo Histórico del Arzobispado de México (AHAM en adelante) caja 36, exp. 15. 
ocupación de las nuevas generaciones, cuyo número superaba el del siglo anterior, y las posibilidades de ocupación real en los espacios eclesiásticos existentes. Aun prelados críticos de la forma en que se ordenaban nuevos clérigos continuaron dando muchas órdenes ante la gran demanda de las familias novohispanas, pero también buscaron salidas. El arzobispo Lanciego Eguilaz se aventuró entonces a revivir la vieja aspiración del clero novohispano de secularizar las doctrinas de indios.

Luego de terminar la visita a su arzobispado y de conocer mejor la situación de toda su clerecía, el arzobispo Lanciego decidió enviar a su secretario, José Ansoain y los Arcos, como procurador a Roma hacia 1721, para tratar varios asuntos sobre doctrinas, incluyendo una propuesta para quitar 60 de ellas a los religiosos. Los puntos que Ansoain trató en Roma tenían como objetivo cuestionar si la posesión de las doctrinas por los regulares aun tenía razón de ser, por un lado, y fijar los alcances que los obispos debían tener en el conocimiento de los frailes al frente de la administración de sacramentos, del movimiento de los mismos de una a otra comunidad religiosa y de las cofradías de doctrinas, por el otro.

Esos temas no eran nuevos, por supuesto; sí lo era que un obispo negociara directamente en Roma la salida de los regulares de las doctrinas indianas, pues como sabemos, los monarcas españoles tradicionalmente eran renuentes a permitir una intervención directa del papado en las Indias, y Felipe V no fue la excepción.

No obstante, el intento secularizador del arzobispo Lanciego tuvo consecuencias, no a corto sino a mediano plazo, por cuanto ayudó a poner en la agenda del primer monarca Borbón la discusión sobre la excepcionalidad de la iglesia de los regulares en Indias, asunto que, combinado con la búsqueda en Roma del patronato universal de la iglesia en España, ponía en la mira casi cualquier viejo o nuevo privilegio papal. ¿Cómo entender de otra manera la negociación de un concordato en 1737, en el que el papa estuvo de acuerdo en que el rey proveería cargos y se quedaría con las rentas de sedes vacantes, así como que la Iglesia ya no estaría exenta de impuestos y que había que reformar al clero y establecer su número? ${ }^{17}$ Aunque por entonces tampoco se llegó a una reforma de la Iglesia, sentó un precedente indudable para el final concordato de 1753. A fin de cuentas, el poder que los monarcas españoles ejercieron en las iglesias indianas fue un parámetro de primer orden para la reforma de la Iglesia en la propia España.

Aunque al final no tuvo éxito, y aun recibió un regaño de Felipe $\mathrm{V}$, dos décadas después de su muerte se inició, en efecto, la recta final de la esperada secularización que Lanciego ayudó a poner en la agenda real. Tales hechos coloca-

${ }_{17}$ J. Lynch, El siglo XVIII. Historia de España, XII, Barcelona, Crítica, p. 100.

Hispania Sacra, LX

122, julio-diciembre 2008, 487-505, ISSN: 0018-215-X 
ron a los frailes en una situación por demás complicada durante el medio siglo previo a la cédula de 1749 que ordenó su separación de las doctrinas.

Pasemos a examinar los argumentos: las juntas de Madrid y la cédula de 1749. Manuel Rubio Salinas, arzobispo electo de México en 1748 y convocado a las juntas de Madrid, sin conocer de cerca la realidad novohispana, se convenció que la clerecía del arzobispado, especialmente los regulares, necesitaban de una reforma profunda. Para llegar a tal conclusión, los ministros del rey aportaron toda la información disponible para ese efecto. Sabedor el arzobispo electo de que desconocía la realidad indiana, el secretario del consejo le entregó un resumen de las principales disposiciones papales y de las cédulas que sobre fundación y regulación de conventos y doctrinas había desde el siglo XVII hasta 1739 al menos. El escrito buscaba demostrar la vigencia de un breve de Paulo V, ordenando reconocer como «convento» sólo a aquellas casas con al menos ocho frailes, así como la de otras disposiciones que expresaban que toda fundación con menos de ocho religiosos debía considerarse «doctrina» y por tanto sujeta al ordinario. Igualmente, al arzobispo se le dio a conocer una representación al papa en la cual la corona definía así la situación de las parroquias de regulares en América:

[...] la necesidad que padecen las iglesias parroquiales...porque siendo a quien debemos reconocer más obligaciones, por recibir en ellas la fe por el bautismo, y ser a quien por derecho toca la administración de sacramentos, son las más olvidadas y las más pobres, siendo la causa principal el haberse introducido las religiones en el excesivo número de religiosos, procurando todos enriquecer los conventos, solicitando entierros y fundaciones de obras pías temporales y perpetuas y que sus iglesias sean frecuentadas, con que no sólo se ha quitado a los curas y beneficiados mucho de los derechos parroquiales y otros emolumentos precisos para sustentarse, sino que las mismas parroquias han venido a quedar desiertas y a tener tanta miseria que es fuerza se sirva sin la decencia y ornamento conveniente, siendo de sumo sentimiento que las que habían de ser más socorridas y frecuentadas, como madres de todos y de las religiones, estén tan solas y necesitadas que en muchas no hay lo necesario para la limpieza de los altares, teniendo todas las religiones tan suntuosos edificios, tan ricos ornamentos y tantos adornos de plata y oro que parece que exceden a la pobreza religiosa $[\ldots]^{18}$.

La imagen antes descrita sobre los conventos y las doctrinas indianas que ofrecían los ministros del rey era, indudablemente, una generalización, una reducción de la gama de realidades que en los hechos presentaban en el continente americano. Y formaba parte de la serie de argumentos que en España se manejaban para justificar la reforma del clero regular que por entonces se iniciaba. El aparente «saqueo» de las doctrinas por los conventos, en detrimento del cul-

18 AHAM caja 104 CL, libro 3, sin foliar, «Representaciones hechas a su majestad sobre doctrinas de los regulares», 1748-1753. 
to, expresado en el texto no se corresponde con lo que sucedía en el arzobispado de México, en donde, durante la primera mitad del siglo XVIII disfrutaron de más rentas que los curatos de clérigos. Tal acusación era más un argumento político que un examen objetivo de la realidad indiana.

Con tal opinión del clero regular indiano, por orden real de 29 de noviembre de 1748, se iniciaron las reuniones de las juntas previas a la cédula de 1749 en casa de José Carvajal y Lancaster, secretario de Estado ${ }^{19}$. La junta, compuesta por ministros del rey y los arzobispos electos de México y Lima, tuvo como principal resultado proponer la secularización de las doctrinas de religiosos en Indias. Los principales argumentos fueron la relajación de los votos monacales y la independencia que mostraban ante cualquier autoridad, incluyendo la real. Los arzobispos electos de México y de Lima tuvieron un papel muy activo al presentar varios pareceres que incidieron directamente en las futuras decisiones del monarca. El regalismo fue la doctrina política predominante durante las sesiones.

La idea defendida por los arzobispos de México y Lima fue hacer patente «... el lastimoso estado en que se halla el eclesiástico regular de aquellos reinos, los deplorables efectos que esto produce y la ingente necesidad de remedio...» ${ }^{20}$. Esta idea contrasta notablemente con la opinión que, en general, tenían los alcaldes mayores de la provincia de México. Coincidían estos en que los doctrineros eran frailes bondadosos que cumplían muy bien con sus deberes religiosos para con su feligresía $^{21}$. Los miembros de la junta, luego de expresar lo «arduo» de su tarea ante «lo poderoso del gremio», describieron así al clero regular indiano:

[...] su crecido número de individuos, su opulento nervio de haciendas, sus inagotables medios para los recursos, y su facilidad para ser admitidos es tal, que no hay obispo que en defensa de su dignidad, y lo más principal, para el mejor gobierno de las almas y pasto espiritual de sus ovejas, quiera reducirlos a los términos a que deben contenerse, que no quede rendido en la contienda, cuando no sea abatido y despreciado, pues no hay autoridad que no disputen, potestad que no se arroguen y jurisdicción que no se atribuyan [...] hemos puesto toda nuestra atención en discurrir los medios de arrancar el cáncer que tanto se ha apoderado de aquel cuerpo $[\ldots]^{22}$.

Nuevamente, la imagen descrita antes sobre el «gran poder» que representaba el clero regular y la «debilidad» de los obispos para defenderse constituía,

19 J. LYNCH, El siglo XVIII..., p. 145. Años atrás Carvajal había trabajado en el Consejo de Indias.

${ }^{20}$ AHAM caja $104 \mathrm{CL}$, libro 3, sin foliar, «Representaciones hechas a su majestad sobre doctrinas de los regulares», 1748-1753.

${ }^{21}$ Relaciones geográficas del arzobispado de México.1743. Colección Tierra Nueva y Cielo Nuevo. Edición de Francisco de Solano. V Centenario del Descubrimiento de América. Madrid, CSICDpto. de Historia de América, 1988, tomo II.

22 AHAM caja 104 CL, libro 3, sin foliar, «Representaciones hechas a su majestad sobre doctrinas de los regulares», 1748-1753.

Hispania Sacra, LX

122, julio-diciembre 2008, 487-505, ISSN: 0018-215-X 
indudablemente, una simplificación de las realidades indianas; al menos en el arzobispado de México, entre 1700 y 1749 los arzobispos habían ganado mucho terreno frente a los regulares, según vimos antes.

Para remediar la situación del clero regular indiano, los arzobispos pidieron tramitar una bula papal confirmando una anterior de Inocencio XI, que ordenó a los conventos no tener más religiosos de los que sus fondos y rentas pudieran mantener. Además, los prelados regulares deberían avisar al ordinario cuando fueran a dar un hábito y para suprimir conventos con rentas insuficientes. Los arzobispos insistieron en el relajamiento de costumbres de los religiosos, por lo cual la junta propuso exigir a los religiosos obedecer su regla.

Sobre los excesos de curas y doctrineros, tema que aquí nos ocupa, expresaron que ningún remedio sería suficiente «...que no sea sacando bula que extinga los curatos de regulares con aprobación de los virreyes...»; para evitar reacciones escandalosas de los religiosos, el rey debía obtener otra bula inhibiendo a los prelados regulares «...de cualquier conocimiento de causa o acto de visita de sus religiosos párrocos, sujetándolos in omnibus a la punición, castigo y corrección de los ordinarios...» Además, los virreyes debían suspender el nombramiento de curas regulares en tanto se obtenían las bulas y detener cualquier breve en contrario, aunque lleven el pase del consejo, a quien se le debía prohibir conocer del asunto, y dejar obrar en armonía a virreyes y obispos. El rey, insistían, debía usar de sus «amplias facultades» en Indias. Al final se pedía que los obispos no fueran otra vez víctimas de los religiosos, quienes «... se ven sostenidos de la indiscreta devoción o piedad de los pueblos...».

Estas primeras propuestas de la junta de noviembre de 1748 apuntaban, en efecto, a coartar cualquier posibilidad de defensa de los doctrineros: secularizar, con apoyo de los virreyes, todas las doctrinas; sujetar a los doctrineros solo a la jurisdicción del ordinario, y finalmente, cuidarse del apoyo popular que podían recibir los religiosos. En efecto, tradicionalmente en Nueva España los virreyes habían apoyado a las órdenes religiosas, al menos hasta Carlos II, pues ya bajo Felipe V, el monarca exigió a prelados y virreyes actuar en completa armonía, como se había hecho después de 1700 . En cuanto al temido apoyo del pueblo a los frailes ante una eventual separación de sus doctrinas, las cosas habían cambiado también, pues las feligresías distaban mucho de ser aquellas comunidades de indios sujetas solamente a los evangelizadores del siglo XVI.

Interesa e parecer del arzobispo sobre las doctrinas de marzo de 1749. Las conclusiones de la junta de 1748 fueron apenas el principio de las discusiones. En los meses siguientes siguieron enviándose pareceres a Fernando VI. El arzobispo de México siguió teniendo una participación activa. A principios de marzo de 1749 emitió su opinión personal sobre la cuestión de las doctrinas indianas y su futuro inmediato. De inicio, Rubio Salinas insistió, como muchos otros 
antes, sobre el estado de excepción de los religiosos en su papel de cura de almas. Y si ello había sido así se debía a las condiciones de la evangelización inicial en Indias y al permiso expreso de Roma ${ }^{23}$. La presencia misma de los religiosos en Indias sólo podía explicarse por la anuencia del papa y de los reyes españoles ${ }^{24}$. Por ello, añadía el arzobispo, el oficio de párrocos que los religiosos habían ejercido fue, desde un inicio, provisional, mientras no hubiera clérigos suficientes e idóneos para sustituirlos ${ }^{25}$. De esta premisa, el prelado deducía que las doctrinas nunca fueron en realidad beneficios o propiedad de las órdenes religiosas y que el rey quedó siempre con la libertad de removerlos ${ }^{26}$.

El arzobispo trató también el asunto de la situación del clero secular. Afirmó que con la secularización de las doctrinas más clérigos se aplicarían al estudio y a la virtud, con la esperanza de lograr un curato ${ }^{27}$. Ademásun cura beneficiado cuidaría mejor de los indios que un doctrinero que podía ser removido por su prelado en turno ${ }^{28}$. Al final de este argumento, Rubio Salinas declaraba sin am-

${ }^{23}$ AHAM caja $104 \mathrm{CL}$, libro 3 [...] a los regulares esta prohibida por derecho canónico la obtención de beneficios curados seculares... por lo cual es preciso que para servirlos dispense el sumo pontífice que suele hacerlo, concurriendo legítima causa como lo es la necesidad o utilidad de la iglesia y la inopia de clérigos [...].

${ }^{24}$ AHAM caja 104 CL, libro 3 [...] Movidos de esta última causa, dispensaron algunos pontífices con los regulares que pasaron a Indias con orden o permiso de nuestros católicos reyes [...].

${ }^{25}$ AHAM caja $104 \mathrm{CL}$, libro 3 [...] para que en aquellas partes pudiesen ejercer el oficio de párrocos, según consta de las bulas de León X, Adriano VI, Paulo III y Clemente VII, y de varias cédulas reales que cita el señor Solórzano, libro 3 Política Indiana, cap. 16, lo cuales uniformemente advierten que dichos curatos se proveían en los regulares, para que los obtuviesen precariamente y como en deposito, hasta que hubiese sacerdotes seculares suficientes en número y capacidad para poder regirlos y administrarlos [...].

${ }^{26}$ AHAM caja 104 CL, libro 3 [...] poniéndose en todas las referidas cédulas la expresa caución de que nunca pudiesen los regulares adquirir derecho alguno en cuanto a la propiedad y perpetuidad de los dichos curatos y doctrinas, sino que habían de quedar siempre amovibles ad nutum de s. m., para podérselas quitar a los regulares los mencionados curatos y proveerlos en clérigos, una vez que se verifique haber cesado la causa impulsiva de las dispensaciones pontificias, que dispensaron a los religiosos ejercer el oficio de párrocos por inopia de clérigos, pues no habiendo este motivo, entra en tal caso la disposición del texto en capítulo $1^{\circ}$. De capell. Monas., y la doctrina del señor Urritigoiti in pastor reg. Part. 2 q. 21 a num. 13 os que ad 18 en donde cita muchos textos y autores para el mismo fin, y el señor Solórzano en el lugar citado extiende algunas poderosas razones para persuadir las utilidades que se seguirían si se removiese a los regulares de los beneficios curados [...].

27 AHAM caja 104 CL, libro 3 [...] Lo que comprende mi cortedad es, que si esta providencia tuviese efecto, a vista de ella, y con la esperanza de lograr algunas conveniencias, se animarían los naturales de aquellas partes a los estudios, se dedicarían más a la virtud y a obrar de suerte que fuesen dignos de obtener el cargo de curas, de lo que tal vez muchos de ellos estarán retirados por la corta esperanza de premio [...].

${ }^{28}$ AHAM caja 104 CL, libro 3 [...] También parece que de esta suerte estarían los curatos más bien servidos y los indios mejor tratados, pues para ser mejor recibidos de ellos los clérigos, que los regulares, llevan la ventaja de entrar en ellos como en viña propia, que han de cultivar sin otro término que el que sus buenas costumbres y procedimientos les adelantare, para mejores en otro curato y de esta suerte los indios aseguran ser bien tratados y defendidos de su cura, y no puede dejar de conocerse que

Hispania Sacra, LX

122, julio-diciembre 2008, 487-505, ISSN: 0018-215-X 
bages que el rey podía remover a los doctrineros: «...por el derecho de patronato y en virtud de la caución con que a los regulares se entregaron los citados curatos o doctrinas, puede su majestad quitárselos y proveerlos en clérigos...»

Luego de presentar todas estas justificaciones, el prelado de México propuso las formas para la remoción de los religiosos, y en ese renglón demostró tener un agudo tacto político y sugirió tomar las precauciones necesarias para evitar pleitos y escándalos, pensando no tanto en los promovidos por los frailes sino por los mismos indios ${ }^{29}$. La primera precaución era «averiguar si en aquello reinos habrá clérigos suficientes en número y capacidad para el ejercicio de párrocos, lo cual no se puede puntualmente saber sin que el tiempo y la experiencia lo manifiesten; porque aunque el número sea grande puede ser el de los hábiles muy corto $[\ldots]^{30}$.

No bastaría saber el número y la formación de los clérigos que sustituirían a los frailes. Habría que conocer su vocación eclesiástica, pues temía que, de removerse a todos los religiosos juntos, no tendrían el suficiente número de candidatos idóneos para sustituirlos, por todo lo cual proponía actuar paso a paso ${ }^{31}$. No explica el documento cómo iban a medir las vocaciones eclesiásticas, asunto por demás complicado.

Insistía en que los virreyes debían suspender el nombramiento de frailes en las doctrinas vacantes, no obstante que ya hubieran sido antes escogidos por sus prelados, y que se inhibiera a los prelados regulares de visitar las doctrinas, pues este derecho sólo debía corresponder a la jurisdicción ordinaria, tanto para vigilar la conducta de los doctrineros como su administración espiritual, con el poder incluso de removerlos y sustituirlos por clérigos, contando con la aprobación del virrey.

Al final de su parecer, y luego de expresarse también sobre limitar la adquisición de bienes por los religiosos, Rubio Salinas aceptó que, debido a su falta de conocimiento práctico sobre el arzobispado que pronto iba a gobernar, los medios que había sugerido tal vez causaran más estragos que la enfermedad,

los obispos cuya obligación no tiene el término que la de un provincial, pondrán con mayor entereza el remedio que convenga [...].

${ }^{29}$ AHAM caja 104 CL, libro 3 [...] soy de sentir que se proceda en este negocio con la más prudente pausa por evitar los gravísimos inconvenientes que puede producir lo contrario y sería desgracia que siendo el principal objeto a que mira esta providencia el bien espiritual de aquel país, se convirtiera su ejecución en daño de lo que tanto importa [...].

${ }^{30}$ AHAM caja 104 CL, libro 3.

31 AHAM caja 104 CL, libro 3 [...] Estas y otras reflexiones que tendrá prevista la superior comprensión del ministerio, manifiestan los inconvenientes que puede producir el ejecutar de una vez esta mutación y aconsejar en este asunto el pausado procedimiento que tuvieron por conveniente el señor Solórzano y otras personas graves y doctas que cita. Supuesto pues, que conduce proceder en la materia con lentitud $[\ldots]$. 
por lo cual anunciaba que, de ser así, sobreseería las órdenes reales en espera de mejores disposiciones. Añadía que pondría todo su celo para cumplirlas, y para ello pedía inhibir a la audiencia del conocimiento de todos estos asuntos, «...mandándoles que dejen obrar a los prelados, unidos con los virreyes, cuanto les parezca conveniente...» para evitar escándalos con los religiosos «...y más si hallan quien patrocine sus recursos...» ¿Qué tanto hizo caso Fernando VI de las opiniones del arzobispo electo de México?

Hacia el 4 de octubre de 1749, a un año de iniciadas las juntas sobre la reforma del clero regular y la secularización, Fernando VI se decidió finalmente a ordenar, mediante real cédula, la secularización de las doctrinas de religiosos en los arzobispados de México, Lima y Santa Fe. La cédula resultante es un documento por demás interesante por cuanto refleja, por un lado, la influencia que los argumentos de las juntas tuvieron en la actitud guardada por el rey respecto a la secularización, y por otro, el desconocimiento que se tenía de las realidades clericales de las diócesis indianas.

El texto de la cédula, de inicio, recapitula la historia para explicar el porqué los regulares, y no los clérigos, habían permanecido hasta entonces al frente de las parroquias de indios, argumentando como el clero secular indiano había venido repitiendo al menos desde el siglo XVII: la necesidad de contar con ministros para la evangelización habían «obligado» a recurrir a los frailes, pero siempre de forma provisional, en tanto hubieran clérigos suficientes e idóneos ${ }^{32}$.

Esta medida, declaraba la cédula, había ocasionado con el tiempo la desviación de la cabal observancia religiosa, pero ante la multiplicación de doctrinas y la insuficiencia del clero secular, se siguió postergando el traspaso de las parroquias, las mismas que los religiosos siempre mantuvieron «precariamente».

Hasta aquí la justificación histórica y enseguida, la «nueva etapa» que vivía el clero secular en la época de Fernando VI, tanto en «suficiencia» como en «idoneidad». Ante ello, declaraba el rey: «...ha parecido conveniente no dilatar más tiempo el acudir a remediar el daño que lamentan las mismas religiones en la intolerable dispersión de sus hijos...» Para tomar las mejores disposiciones, agregaba el monarca, había convocado a la junta de notables, «...compuesta de teólogos y ministros de mi satisfacción, dotados de las precisas calidades, que me propusiesen en conciencia los medios que considerasen más conformes y convenientes al servicio de Dios y mío...»

Para Fernando VI, los miembros de la junta habían hecho gala de un conocimiento «práctico» de tal modo que había prevenido los inconvenientes de llevar

32 AHAM caja 104 CL, libro 3: [...] se halló conveniente y aun preciso, advertida la falta de clérigos seculares, dejar encomendados en precario las doctrinas y curatos que se iban erigiendo, para disponer y proporcionar el pasto espiritual de aquellas almas, a los regulares con que proveyeron las religiones de estos reinos a la necesidad de operarios que trabajasen a su reducción y conversión [...].

Hispania Sacra, LX

122, julio-diciembre 2008, 487-505, ISSN: 0018-215-X 
a efecto la secularización, y así, se habían previsto mejor las disposiciones. En las siguientes líneas, el monarca ordenó iniciar la remoción de los religiosos retomando la propuesta del arzobispo de México; es decir:

[...] por el modo más fácil y adaptable a las circunstancias presentes, se de principio a la separación de los regulares de algunos curatos que fueren vacando, confiriéndolos a clérigos seculares idóneos y de las circunstancias y suficiencia convenientes y precisas, debiendo sólo entenderse la providencia por ahora en ese arzobispado y el de Lima, y extenderse al de Santa Fe, para que de norma y regla el suceso de ellos cuando se discurra conveniente la práctica en los demás $[\ldots]^{33}$.

La gradualidad propuesta por el arzobispo de México fue, como se lee, bien acogida por el monarca, previendo los conflictos sociales que podían generarse con la separación de los doctrineros. Y aquí cabe una pregunta fundamental: ¿por qué se escogió precisamente «experimentar» en principio en los arzobispados de México y Lima? Los documentos nada dicen, aunque pueden inferirse algunas posibles explicaciones. Por ser las sedes del poder virreinal y arzobispal, se esperaría que ante las máximas autoridades de los virreinatos los religiosos no se indispusieran en gran medida, además de que serviría de ejemplo al clero regular del resto de las diócesis. Pero, al menos para el caso del arzobispado de México, considero que había por lo menos mejores condiciones para iniciar la secularización siendo la principal el que ahí el poder de los doctrineros ya estaba muy desgastado.

De tales condiciones lo más seguro es que no estuvieran muy concientes en Madrid, hacia 1749, y sí en cambio seguía vigente la idea de un clero regular fuerte, influyente y con todo el respaldo de «los pueblos», como se comentó en alguna de las juntas previas. De ahí la reiteración en la cédula para que tanto el arzobispo como el virrey actuaran con el mayor sigilo y cuidado ${ }^{34}$. Para ello, las primeras secularizaciones debían hacerse sólo en doctrinas vacantes, y de preferencia en las menos importantes, esperando poca o ninguna protesta de los regulares; el siguiente paso sería ir quitándoles parroquias de más importancia, calculando el menor escándalo posible. Otra medida precautoria sería que sólo el arzobispo y el virrey tomarían las decisiones, sin permitir ninguna otra intromisión. Una más: que el contenido de la cédula de ninguna manera debía darse a conocer a las religiones, para evitar que interpusieran más recursos, sin embargo, insiste el rey, «...del ningún derecho que tienen a mantener los curatos y

\footnotetext{
${ }^{33}$ AHAM caja 104 CL, libro 3.

${ }^{34}$ AHAM caja 104 CL, libro 3: [...] Para conseguir el fin con más precaución de parte de la misma providencia y menos reparo y advertencia de las religiones se ha discurrido podrá conducir se comience la separación por alguno o algunos de los curatos que vacaren, y que por su menor renta, mayor distancia u otras consideraciones sean menos apreciables a las mismas religiones, y no tan sensible la privación de ellos [...].
} 
doctrinas...» $\mathrm{Al}$ final, la cédula ordenaba al arzobispo que tuviera siempre informado personalmente al rey sobre los avances de la secularización.

A escasos años de la aplicación de la cédula de 4 de octubre de 1749, el arzobispo de México, Manuel Rubio y Salinas informaba del avance exitoso de la secularización en su arzobispado. Hacia 1752, el prelado informó a Ensenada de la secularización de otras doce doctrinas, agustinas y dominicas «...sin leve conmoción ni desagrado de los indios, poniendo en sus curatos a los clérigos más dignos, exponiendo vuestra señoría quedaba en ejecutar lo mismo con las demás doctrinas que vacaren por muerte de los curas ministros u otro justo título...» Ante tales «éxitos», el rey había decidido extender la aplicación de la cédula de 1749 a todos los obispados indianos, mediante cédula de $1^{\circ}$. de febrero de $1753^{35}$.

¿Por qué el traspaso de las doctrinas en el arzobispado mexicano había avanzado sin tropiezos, a pesar de una larga historia de conflictos y de fracasos por parte del episcopado novohispano para secularizarlas? Para el arzobispo, era claro que la prudencia y la gradualidad con la que había actuado, junto con el virrey, al ir quitando doctrinas vacantes o cuyo cura doctrinero no tuviera título autorizado, explicaban el éxito de las operaciones, y así lo había defendido en Madrid. No obstante, el asunto era más complejo, pues las causas que explican el éxito deben buscarse desde algunas décadas atrás en la misma jurisdicción.

A manera de conclusión, al contrastar los argumentos vertidos en las juntas de Madrid y la cédula de 1749 con los cambios ocurridos en el arzobispado de México durante la primera mitad del siglo XVIII queda claro que las medidas decretadas por Fernando VI sobre las doctrinas indianas tuvieron de fondo, principalmente, razones políticas, más que una necesidad real de reforma del clero regular, en primer lugar, porque el concepto del clero regular manejado en las juntas y en la cédula hacia tabla rasa de las diferencias regionales americanas, generalizando «excesos» en la administración parroquial de que no hay evidencias claras en el arzobispado. Considero que en realidad las tendencias regalistas de Fernando VI, iniciadas por su antecesor en buena medida, reclamaron en 1749 dar un importante paso en Indias, como preámbulo al patronato universal de 1753. Y ese paso fue precisamente reducir la presencia de los regulares en las sociedades hispanoamericanas, personajes que a pesar del evidente desgaste de su poder, seguían representando un obstáculo al ejercicio pleno del real patronato.

Más allá de lo argumentado en las juntas de Madrid, lo que se vivió en el arzobispado de México en las décadas previas a 1749 fue una decadencia notable

${ }^{35}$ D. A. Brading, Una Iglesia asediada: el obispado de Michoacán, 1749-1810. México, Fondo de Cultura Económica, 1994, p. 77.

Hispania Sacra, LX

122, julio-diciembre 2008, 487-505, ISSN: 0018-215-X 
del poder de los regulares al frente de las doctrinas que explican en buena medida la rapidez de la secularización. Si bien es cierto que la cautela política que demostró el arzobispo Rubio Salinas y el apoyo de los virreyes durante la aplicación de la cédula de 1749 fue vital, también lo es que los tres arzobispos precedentes y los cambios de las feligresías se habían encargado de minar paulatinamente la jurisdicción y el poder social del clero regular a cargo de la administración de sacramentos.

El cobro del subsidio eclesiástico, por ejemplo, puso las bases para el establecimiento definitivo de los jueces eclesiásticos en las doctrinas, arrebatando a los frailes la jurisdicción que tradicionalmente habían ejercido. El crecimiento de las feligresías parroquiales no fue únicamente numérico, sino también cualitativo en cuanto a su composición social; este fenómeno provocó que españoles y mestizos, antes ausentes en las doctrinas, pudieran promover cambios en la organización parroquial de varios partidos del arzobispado. Igual, y gracias a la información que sobre las rentas de todas las parroquias resultó por el cobro del subsidio, los arzobispos pudieron comprobar con certeza la mayor riqueza de las doctrinas con respecto a los curatos de clérigos, dando más sustento al reclamo histórico de traspasar las doctrinas.

Simultáneamente a los cambios operados en torno a las doctrinas, podemos observar en el clero secular del arzobispado de México también unas dinámicas favorables a la secularización. El aumento de la población clerical y sus expectativas de empleo, y el desfase cada vez más evidente con el lento crecimiento de cargos reales ocasionaron tensiones en ciertos enclaves clericales. El mejor ejemplo fue el de lo ocurrido en la ciudad de Querétaro.

Finalmente hay que destacar que fue el arzobispo José Lanciego Eguilaz el más sensible a las necesidades de su clerecía y, en consecuencia, el prelado que más intentos hizo por reducir los espacios de los regulares a favor de los clérigos. Reforzó la autoridad de los jueces eclesiásticos, creando con ello más empleos. Propuso convertir las misiones en doctrinas para tener más control de ellas. Favoreció la división de curatos y doctrinas y, finalmente, intentó la secularización de 60 doctrinas.

Esta última acción es de especial importancia pues, aunque no prosperó entonces, puso en la agenda real el asunto, sobre todo el argumento de que el rey podía en cualquier momento elegir entre frailes y clérigos a los curas de cualquier parroquia en Indias, el mismo que salió a relucir en las juntas de Madrid.

A fin de cuentas, el clero secular, por depender en mucha mayor medida del real patronato que el regular, resultó favorecido, pues con ello la monarquía española mejoraba sus condiciones para obtener mayor provecho de las iglesias indianas. 